\title{
TGF- $\beta 1$-Induced Pulmonary Fibroblasts Proliferation and Differentiation Are Inhibited by Antisense Oligodeoxynucleotide of Basic Fibroblast Growth Factor
}

\author{
Weijun Tan, Qiuyue Tan, Ting Wang and Zhenshun Cheng* \\ Department of Respiratory Medicine, ZhongNan Hospital of WuHan University, \\ WuHan 430071, China
}

Received December 16, 2014; accepted June 14, 2015

\begin{abstract}
Summary The objective of this study is to investigate the role of antisense oligodeoxynucleotide (ASODN) of basic fibroblast growth factor (bFGF) in the proliferation, differentiation and collagen synthesis of pulmonary fibroblasts (PFs) and the possible mechanism. PFs were isolated from male Wistar Rat and transfected with antisense oligodeoxynucleotide or sense oligodeoxynucleotide (SODN) of bFGF for four experimental conditions: (1) control group: PFs without TGF- $\beta 1$; (2) TGF- $\beta 1$ group: PFs with TGF- $\beta 1$; (3) TGF- $\beta 1+$ ASODN group: ASODN transfected PFs with TGF- $\beta 1$; and (4) TGF- $\beta 1+$ SODN group: SODN transfected PFs with TGF- $\beta 1$. Proliferation of PFs was monitored by growth curves and MTT assays, expression of $\alpha$-smooth muscle actin ( $\alpha$-SMA) was evaluated by immunocytochemistry, concentrations of bFGF, CTGF, and Type I collagen in culture supernatants were determined by ELISA, and mRNA expression of Smad3, Smad7 and Type I collagen in pulmonary fibroblasts was detected by RT-PCR. We found that SODN of bFGF increased cell proliferation of PFs, enhanced the expression level of bFGF, CTGF, $\alpha$-SMA, type I collagen and Smad3. However, ASODN of bFGF had the opposite effects. However, Smad7 was increased in TGF- $\beta 1+$ SODN group but decreased in TGF- $\beta 1+$ ASODN group. The proliferation, differentiation, and collagen synthesis of PFs could be promoted by bFGF and inhibited by ASODN of bFGF which may be related to the regulation of TGF- $\beta 1$-Smad signaling pathway.
\end{abstract}

Key words Basic fibroblast growth factor, Antisense oligodeoxynucleotide, Pulmonary fibroblast, Proliferation, Differentiation.

Idiopathic pulmonary fibrosis (IPF) is a chronic, progressive disease with a rotten prognosis for which, until recently, there were no effective treatments. Pathologically, IPF is characterized by general interstitial pneumonia with excessive fibroblast proliferation and the deposition of large amounts of extracellular matrix (ECM) in the interstitium and matrix remodeling, which leads to distortion of the alveolar architecture, progressive declines in lung function, and ultimately, loss of lung function (American Thoratic Society and European Respiratory Society 2002, Noble et al. 2012).

Pulmonary fibroblasts play an important role in the synthesis of collagens and ECM in the pulmonary interstitium. In idiopathic pulmonary fibrosis, there are numerous fibroblast foci in pulmonary connective tissues. These foci are primarily comprised of pulmonary fibroblasts and myofibroblasts, which differentiate from fibroblasts in the pulmonary interstitium. Both fibroblasts and myofibroblasts predominantly secrete Types I and III collagen, the major components of the ECM (Wolters et al. 2014). TGF- $\beta 1$-Smad signaling pathway is considered to be the most important regulation pathway for proliferation, differentiation and collagen synthesis of pulmonary fibroblasts

*Corresponding author, e-mail: zhenshun_cheng@126.com

DOI: 10.1508/cytologia.80.331 
(Lee et al. 2014).

Basic fibroblast growth factor (bFGF) is a potent chemotactic and mitogenic factor for smooth muscle cells, fibroblasts and myofibroblasts (Davis et al. 1997, Berndt et al. 1995). Previous studies found that quantities of bFGF have been detected in bronchoalveolar lavage fluid and in lung tissue of patients with acute lung injury and pulmonary fibrosis (Henke et al. 1991, Inoue et al. 1996). Mast cells, a major source of bFGF, have been found to aggregate in areas of pulmonary fibroblast hyperplasia in the lungs of patients with chronic pulmonary fibrosis (Qu et al. 1995, Reed et al. 1995). Our previous study also found that mast cells which express high levels of bFGF induced rat pulmonary fibroblast proliferation and differentiation (Cheng et al. 2012). These findings suggested that bFGF was closely related to the proliferation and differentiation of pulmonary fibroblasts. But the effects of bFGF on the proliferation, differentiation and collagen synthesis of pulmonary fibroblasts and the possible mechanism is still unknown. Based on these findings, the present study is designed to investigate the effects of bFGF on the proliferation, differentiation and collagen synthesis of pulmonary fibroblasts by transfecting rat pulmonary fibroblasts with antisense oligodeoxynucleotide (ASODN) and sense oligodeoxynucleotide (SODN) of bFGF in vitro and the relationship with the Smad signaling pathway.

Materials and methods

\section{Ethics statement}

This study was approved by The Medical Animal Care \& Welfare Committee of Zhongnan Hospital, Wuhan University. All animal work in this study was conducted according to relevant national and international guidelines.

\section{Animals}

Ten adult male Wistar rats $(2.5 \pm 0.22$ months old; $211.1 \pm 4.46 \mathrm{~g})$ were purchased from the Laboratory Animal Center of Wuhan University.

\section{Reagents and antibody}

RMPI-1640 medium, fetal bovine serum (FBS), penicillin-streptomycin, 2-mercaptoethanol, phosphate buffered saline (PBS), lipofectamine 2000 and $0.05 \%$ trypsin/0.02\% EDTA solution were obtained from Invitrogen-GIBCO (Grand Island, NY, USA). The recombinant TGF- $\beta 1$ was obtained from R\&D Systems (Minneapolis, MN, USA). The bFGF, Type I collagen ELISA kits and the MTT kits were purchased from R\&D Systems (Minneapolis, MN, USA). The CTGF ELISA kit was purchased from CUSABIO. The anti-mouse $\alpha$-SMA mAb were purchased from Abcam (Cambridge, UK).

\section{Oligodeoxynucleotide}

The antisense oligodeoxynucleotide (ASODN) which was complementary with the gene of bFGF mRNA in rat was synthesized by Augct (Beijing, China). The gene sequence of ASODN was 5'-CGGCAGCCATGGCCC-3' and the oxygen was replaced by sulfur. In addition, the gene sequence of the sense oligodeoxynucleotide (SODN) which was 5'-GGGCCA TGGCTGCCG-3' was synthesized by Augct.

\section{Isolation and culture of primary pulmonary fibroblasts}

Rats were put to death through anesthetizing by intraperitoneal injection of urethane $\left(1 \mathrm{~g} \mathrm{~kg}^{-1}\right)$ and then immersed in disinfectant. Thoracotomy and laparotomy were performed in an aseptic environment and rats were perfused transcardially with $\mathrm{Ca}^{2+}$ and $\mathrm{Mg}^{2+}$ free PBS through the right ventricle. The abdominal aorta was opened and artificial ventilation was provided via endotracheal 
intubation. When the lungs became grey, they were lavaged with $\mathrm{Ca}^{2+}$ and $\mathrm{Mg}^{2+}$ free PBS (50 mL) through the endotracheal tube. The lungs were harvested aseptically and cut into pieces. These pieces were washed with distilled water containing penicillin $(1: 1000)$ and streptomycin $(1: 400)$ and then three times with RMPI-1640 medium. The lung pieces were digested in RMPI-1640 containing $3 \mathrm{mg} \mathrm{mL}^{-1}$ trypsin and $2.5 \mathrm{mg} \mathrm{mL}^{-1}$ DNase I three times at $37^{\circ} \mathrm{C}$ in a $5 \% \mathrm{CO}_{2}$ atmosphere (fresh solution was prepared for each digestion), $30 \mathrm{~min}$ once. After each round of digestion, the supernatant was collected and mixed with an equal volume of RMPI-1640 containing 15\% newborn calf serum (NBCS). This mixture was filtered through a mesh and the solution was centrifuged at $1000 \mathrm{rpm}$ at $25^{\circ} \mathrm{C}$ for $8 \mathrm{~min}$. Cells were re-suspended in RMPI-1640 containing $10 \% \mathrm{NBCS}$ and then seeded into flasks followed by incubation at $37^{\circ} \mathrm{C}$ in a $5 \% \mathrm{CO}_{2}$ atmosphere for $24 \mathrm{~h}$. Adherent cells were pulmonary fibroblasts. Pulmonary fibroblasts were cultured in RPMI 1640 medium supplemented with $10 \% \mathrm{FBS}, 100 \mu \mathrm{g} \mathrm{mL}^{-1}$ L-glutamine, $100 \mathrm{UmL}^{-1}$ penicillin, $100 \mu \mathrm{g} \mathrm{mL}^{-1}$ streptomycin, and $50 \mu \mathrm{M} 2$-mercaptoethanol in an atmosphere of $5 \% \mathrm{CO}_{2}$ and $95 \%$ air at $37^{\circ} \mathrm{C}$.

\section{Identification of primary pulmonary fibroblasts}

Inverted phase contrast microscope was used to observe the morphology of isolated cells. The cover slips that were prepared for the immunohistochemistry were placed into flasks for the adhering of the lung fibroblasts. Cell-coated cover slips were fixed in acetone for $10 \mathrm{~min}$ at $4^{\circ} \mathrm{C}$. Immunohistochemistry using a streptavidin-peroxidase method was performed according to the manufacturer's instructions. The cover slips were washed in PBS and then treated with $3 \% \mathrm{H}_{2} \mathrm{O}_{2}$ in methanol to inactivate endogenous peroxidase. Subsequently, cover slips were blocked with normal goat serum and then treated with primary antibody (anti-vimentin monoclonal antibody) and secondary antibody (biotin-conjugated goat anti-mouse IgG). Subsequently, cover slips were incubated with HRP conjugated streptavidin (S-A/HRP) followed by visualization at room temperature with DAB. Counterstaining was with hematoxylin followed by dehydration and mounting with neutral gum. Cells were observed under a light microscope.

\section{Cell transfection}

The lung fibroblasts from passage 2 which were digested to $1 \times 10^{6}$ cells mL $\mathrm{m}^{-1}$ were seeded in six-well plates with serum-free RPMI 1640 medium. The $100 \mu \mathrm{L}$ RPMI-1640 medium with $100 \mu \mathrm{g}$ ASODN (or SODN) of bFGF and the $100 \mu \mathrm{L}$ RPMI-1640 medium with $4 \mu \mathrm{L}$ Lipofectamine 2000 were mixed uniformly and placed in room temperature for $20 \mathrm{~min}$. The mixture was added in sixwell plates which were cultured in an atmosphere of $5 \% \mathrm{CO}_{2}$ and $95 \%$ air at $37^{\circ} \mathrm{C}$. Four hours later, the $10 \%$ PBS was added in six-well plates. The cells of transfection were obtained $24 \mathrm{~h}$ later. The expression of bFGF was detected by ELISA to verify the success of transfection.

\section{Experimental cell culture groups}

The cells of transfection with ASODN (or SODN) of bFGF and the normal cells from passage 3-4 at a density of $1 \times 10^{4} \mathrm{~mL}^{-1}$ were inoculated to 24 -well culture plates and fused to $70 \%$ confluence in RPMI-1640 medium with 10\% PBS. Four groups were included in this study. (1) Blank control group: PFs were cultured in the RPMI-1640 medium absence of TGF- $\beta 1$. (2) The TGF- $\beta 1$ group: PFs were cultured in the RPMI-1640 medium with $5 \mathrm{ng} \mathrm{mL}{ }^{-1}$ TGF- $\beta 1$. (3) The TGF- $\beta 1+$ ASODN group: PFs transfected with ASODN were cultured in the RPMI-1640 medium with $5 \mathrm{ng} \mathrm{mL}{ }^{-1}$ TGF- $\beta 1$. (4) The TGF- $\beta 1+$ SODN group: PFs transfected with SODN were cultured in the RPMI-1640 medium with $5 \mathrm{ng} \mathrm{mL}^{-1} \mathrm{TGF}-\beta 1$.

\section{Morphology and growth of pulmonary fibroblasts}

The cells from each group were maintained in 24 -well plates for $24 \mathrm{~h}$. The pulmonary fibroblast morphology was observed under an inverted phase contrast microscope. At the same time, 
cells from three wells were collected for the counting of pulmonary fibroblasts number. Counting was performed three times with averaging each day for five consecutive days to generate pulmonary fibroblast growth curves.

\section{MTT assay pulmonary fibroblast proliferation}

Cells were maintained in 24 -well plates for $72 \mathrm{~h}$. Then, cells were collected from three wells for each experimental group by digestion with $0.25 \%$ trypsin at room temperature for $5 \mathrm{~min}$. Cells were washed three times with HBSS to remove trypsin, re-suspended in $1 \mathrm{~mL}$ of culture medium, and $200 \mu \mathrm{L}$ of this suspension was transferred to a 96 -well plate.

Cells were maintained at $37^{\circ} \mathrm{C}$ in a $5 \% \mathrm{CO}_{2}$ atmosphere for $24 \mathrm{~h}$ to allow cells adhere to the microtest plate wall. The supernatant was carefully removed and $80 \mu \mathrm{L}$ of freshly prepared RPMI1640 was added. Cells in each well were incubated with $20 \mu \mathrm{L}$ of MTT solution $\left(5 \mathrm{mg} \mathrm{mL}^{-1}\right)$ for $4 \mathrm{~h}$. Then, the supernatant was removed and $100 \mu \mathrm{L}$ of DMSO was added to each well followed by shaking for $10 \mathrm{~min}$ to dissolve the crystals. Absorbance was measured at $490 \mathrm{~nm}$ with a microplate reader. Results were reported as arbitrary optical density (OD) units.

\section{Detection of $\alpha$-SMA by immunocytochemistry}

Cells in logarithmic growth phase $\left(1 \times 10^{5} \mathrm{~mL}^{-1}\right)$ were seeded on sterile cover slips in a 24well plate followed by incubation for $24 \mathrm{~h}$. When cells confluence reached $90 \%$, the medium was removed and fresh RPMI-1640 medium containing 15\% FBS was added. After incubation for $48 \mathrm{~h}$, $\alpha$-SMA expression was determined by immunocytochemistry using an anti- $\alpha$-SMA mAb according to the supplier's recommendations.

\section{Measurement of bFGF, CTGF, and Type I collagen levels by ELISA}

The PFs, PFs transfected with ASODN, and PFs transfected with SODN were maintained in 24-well plates for $72 \mathrm{~h}$. Then, supernatants were collected and the amounts of bFGF were determined with ELISA kits according to the manufacturer's instructions. Otherwise, the cells from each experiment group were maintained in 24-well plates for $72 \mathrm{~h}$ and supernatants were collected and the amounts of $C T G F$ and Type I collagen were determined with ELISA kits according to the manufacturer's instructions.

Reverse transcription-polymerase chain reaction (RT-PCR) detection for the detection of Smad3, Samd 7 and Type I collagen $m R N A$

Total RNA was isolated using Trizol (Invitrogen, Carlsbad, CA, USA). A one-step RT-PCR was performed using the Super-Script One-Step RT-PCR kit (TaKaRa). According to kit instructions, RNA was reverse transcribed into complementary DNA, followed by PCR. PCR primer was synthesized by Shanghai Institute for Biological Sciences, Chinese Academy of Sciences. The following primers were used for amplification of target transcripts: Smad3 forward 5'-TGA TCC CTC CAA TTC AGA GC-3'; Smad3 reverse 5'-TAA AGA CCTCTA TGCCAACA-3'; Smad7 forward 5'TGT GTCCAA GAGCCC TCCCT-3'; Smad7 reverse 5'-CAC GCCATCCAC TTCCCT T-3'; Type I collagen forward 5'-TGA CTGGAA GAGCGGAGA GT-3'; Type I collagen reverse 5'-GAA TCC ATC GGT CAT GCT CT-3'; $\beta$-actin forward 5'-CAC GAT GGA GGG GCC GGA CTC-3'; and $\beta$-actin reverse 5'-GAA TCCATCGGTCATGCTCT-3'. PCR products were electrophoresed through a $1.5 \%$ agarose gel and then visualized under gel imaging system. The ultraviolet absorbance at $260 \mathrm{~nm}$ was measured, and absorbance ratio of target gene to $\beta$-actin was taken as the relative value of target gene mRNA level.

\section{Statistical analysis}

All data were statistically processed using the SPSS 17.0 software (SPSS Inc., Chicago, IL, 
USA) and were processed as mean \pm SD. The $t$ test was used for two groups' comparison and oneway ANOVA test was used for multiple groups' comparison. $p<0.05$ was considered as statistically significant.

\section{Results}

\section{The identification of lung fibroblasts}

As shown in Fig. 1A, most of the cells were spindle cells, uniformly distributed with good condition. Immunohistochemical staining of vimentin showed that brown granules uniformly distributed in the cytoplasm, which demonstrated the harvest cells were lung fibroblasts (Fig. 1B).

\section{The success of transfection}

As shown in Fig. 2, the expression of bFGF in PFs transfected with ASODN was significantly decreased compared to the normal cells $(p<0.01)$, and the expression of bFGF in cells transfected with SODN was markedly increased compared to the normal cells $(p<0.01)$. This indicated that the cell transfection was successful.

\section{The effects of bFGF on pulmonary fibroblasts proliferation}

Pulmonary fibroblasts were cultured for $5 \mathrm{~d}$ in each group (Fig. 3A). In all groups, the numbers of pulmonary fibroblasts were gradually increased. PFs increased the most rapidly in TFG- $\beta 1+$ SODN group, followed successively by that of in the TGF- $\beta 1$ group, TGF- $\beta 1+$ ASODN group and control group. For all groups, the numbers of pulmonary fi-

A

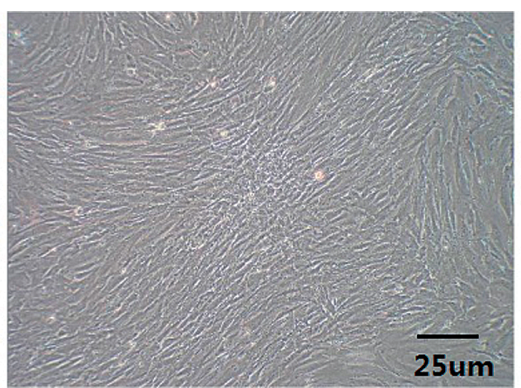

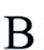

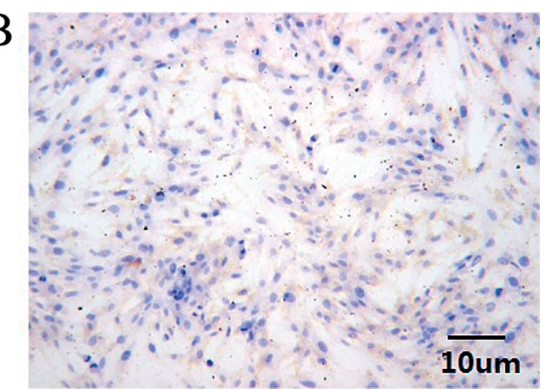

Fig. 1. The identification of lung fibroblasts. A. Cell morphology under the microscope $(\times 100)$. B. Cell morphology of immunohistochemical staining $(\times 100)$.

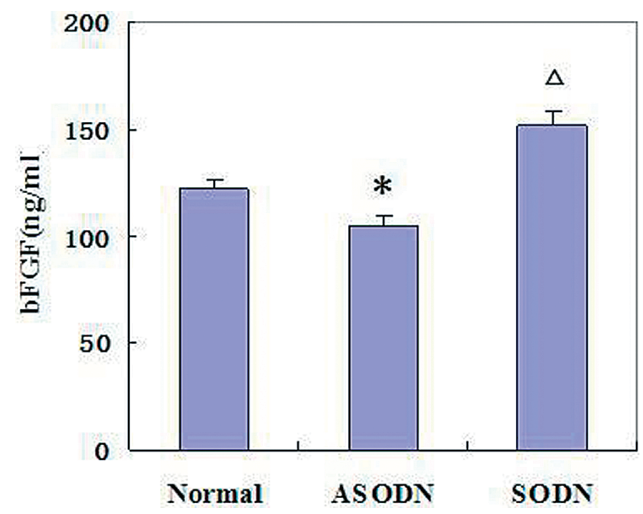

Fig. 2. The expression of bFGF was detected by ELISA. Results were means \pm SEM ( $n=3 /$ group). ${ }^{*} p<0.01$ (vs. normal), ${ }^{\triangle} p<0.01$ (vs. normal). 
(A)

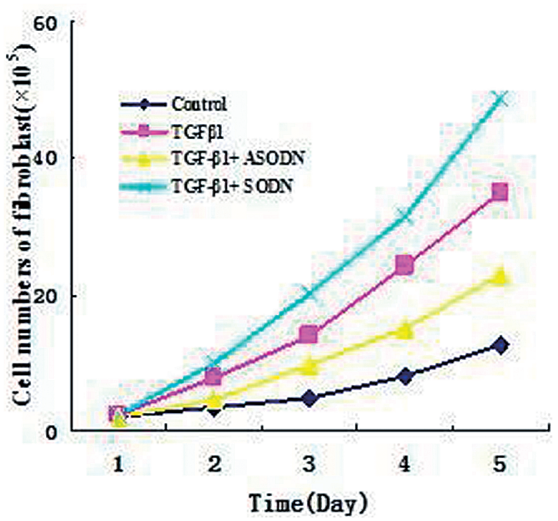

(B)

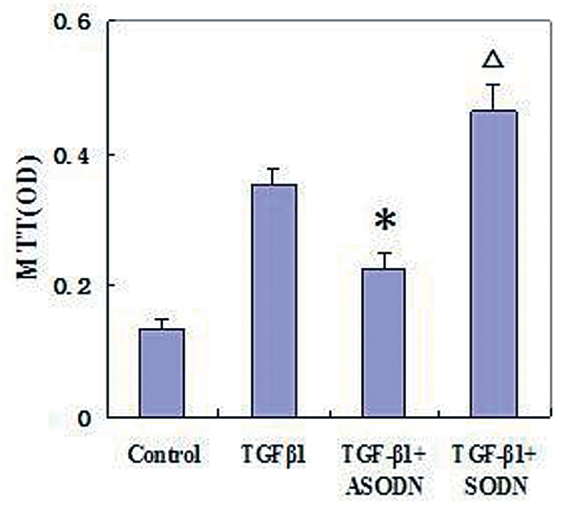

Fig. 3. Pulmonary fibroblast proliferation. The proliferation of pulmonary fibroblasts in control, TGF- $\beta 1$, TGF- $\beta 1+$ ASODN, TGF- $\beta 1+$ SODN groups were determined by (A) changes in cell numbers of fibroblast for $5 \mathrm{~d}$, and (B) MTT assays of pulmonary fibroblast proliferation. Results were means \pm SEM ( $n=3$ /group). In (A), the change in cell numbers of fibroblast by day was significantly different among the four groups by repeated ANOVA measurements $(p<0.05)$. In (B), ${ }^{\triangle} p<0.05$ (vs. control, TGF- $\beta 1$, TGF- $\beta 1+\mathrm{ASODN}$ ), ${ }^{*} p<0.05$ (vs. control, TGF- $\beta 1$, TGF$\beta 1+\mathrm{SODN})$.

broblasts peaked at $5 \mathrm{~d}$ of culture: TGF- $\beta 1+$ SODN group $=(4.867 \pm 0.3512) \times 106$ cells $/$ well, TGF$\beta 1+$ ASODN group $=(2.3 \pm 0.3) \times 106$ cells $/$ well, TGF- $\beta 1$ group $=(3.5 \pm 0.2646) \times 106$ cells $/$ well, control group $=(1.267 \pm 0.3055) \times 106$ cells/well. At $5 \mathrm{~d}$, the numbers of pulmonary fibroblasts in the TGF$\beta 1+$ SODN group were more than those in the control and TGF- $\beta 1$ groups $(p<0.05)$, but the numbers in the TGF- $\beta 1+$ ASODN group were less than those in the TGF- $\beta 1$ group $(p<0.05)$.

After $5 \mathrm{~d}$ of culture, MTT assays were also used to assess fibroblast proliferation (Fig. 3B). The measured absorbance (OD units) for the TGF- $\beta 1+$ SODN group was significantly higher than the control and TGF- $\beta 1$ groups $(p<0.05)$, and the TGF- $\beta 1+$ ASODN group was significantly lower than the TGF- $\beta 1$ group $(p<0.05)$. This suggested that the proliferation of the pulmonary fibroblasts was more active in the TGF- $\beta 1+$ SODN group than in the control and TGF- $\beta 1$ groups, but less in the TGF- $\beta 1+$ ASODN group than in the TGF- $\beta 1$ group.

\section{Detection of $\alpha-S M A$ in pulmonary fibroblasts}

The expression of $\alpha$-SMA was detected by immunocytochemistry (Fig. 4). Representative photomicrographs of $\alpha$-SMA expression are shown in Fig. 4 for the (A) control group, (B) TGF- $\beta 1$ group, (C) TGF- $\beta 1+$ ASODN group, and (D) TGF- $\beta 1+$ SODN group (darker color indicates more intense staining). In the control group, only a few cells were positive for $\alpha$-SMA. In the TGF- $\beta 1$ and TGF- $\beta 1+$ SODN groups, large numbers of cells exhibited positive staining for $\alpha$-SMA in the cytoplasm, but compared to the TGF- $\beta 1$ and TGF- $\beta 1+$ SODN groups, the cells exhibited positive staining for $\alpha$-SMA in TGF- $\beta 1+$ ASODN group were decreased. Figure 4E showed that the integrated optical density (IOD) for $\alpha$-SMA expression in the TGF- $\beta 1+$ SODN group was dramatically higher than the TGF- $\beta 1$ and control groups $(p<0.05)$, and the IOD of the TGF- $\beta 1+$ ASODN group was higher than the control group but lower than the TGF- $\beta 1$ group $(p<0.05)$. It suggested that the differentiation form pulmonary fibroblast into myofibroblast was increased in the TGF- $\beta 1+$ SODN group and decreased in the TGF- $\beta 1+$ ASODN group compared to the TGF- $\beta 1$ group.

\section{Cell culture production of CTGF and Type I collagen}

As shown in Fig. 5, the concentrations of CTGF (Fig. 5A) and Type I collagen (Fig. 5B) were 

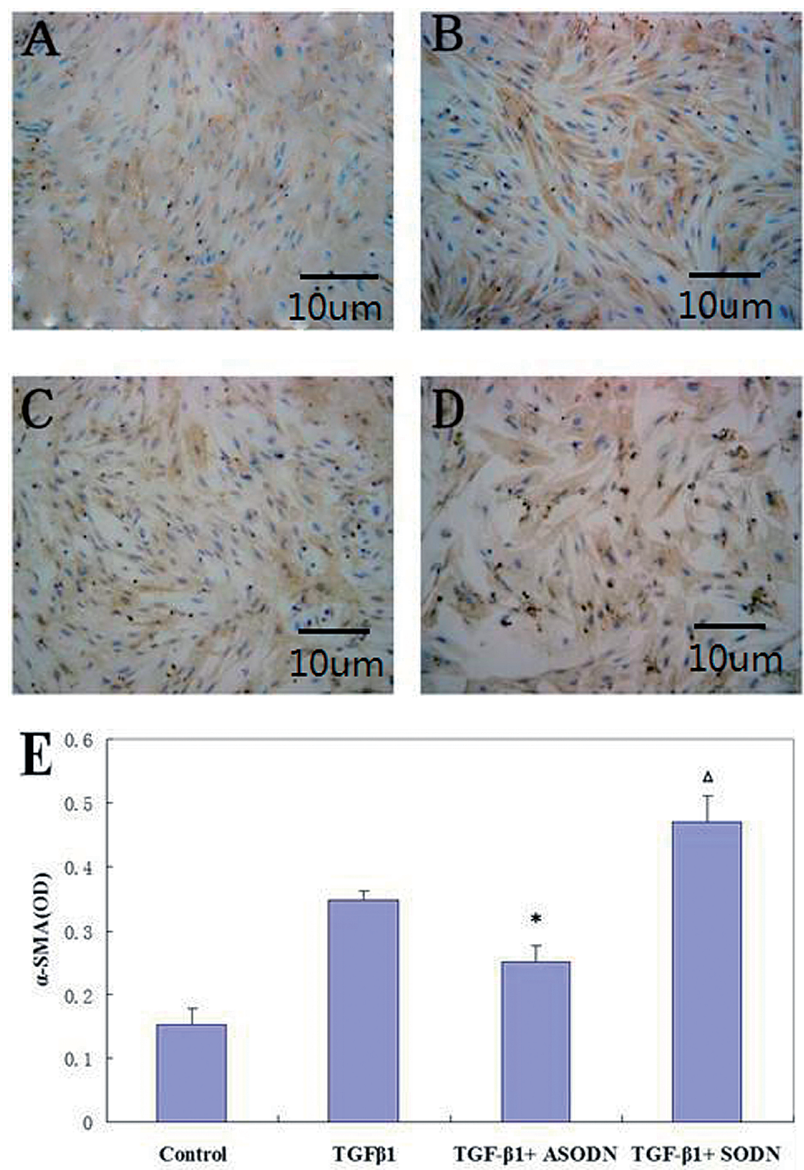

Fig. 4. The expression of $\alpha$-SMA was detected by immunocytochemistry. Representative photomicrographs showing $\alpha$-SMA staining results $(\times 100)$ for (A) control group, (B) TGF- $\beta 1$ group, (C) TGF- $\beta 1+\mathrm{ASODN}$ group, and (D) TGF- $\beta 1+\mathrm{SODN}$ group. (E) Integrated optical density (IOD) readings for $\alpha$-SMA staining. Results were means \pm SEM ( $n=3$ /group). $\alpha$-SMA expression levels were: control group $=0.153 \pm 0.0252$, TGF- $\beta 1$ group $=0.347 \pm 0.0153$, TGF- $\beta 1+$ ASODN group $=0.25 \pm 0.0265$, TGF $-\beta 1+\mathrm{SODN}$ group $=0.47 \pm 0.04,{ }^{\triangle} p<0.05$ (vs. control, TGF- $\beta 1$, TGF$\beta 1+\mathrm{ASODN}),{ }^{*} p<0.05$ ( $v s$. control, TGF- $\beta 1$, TGF- $\left.\beta 1+\mathrm{SODN}\right)$.
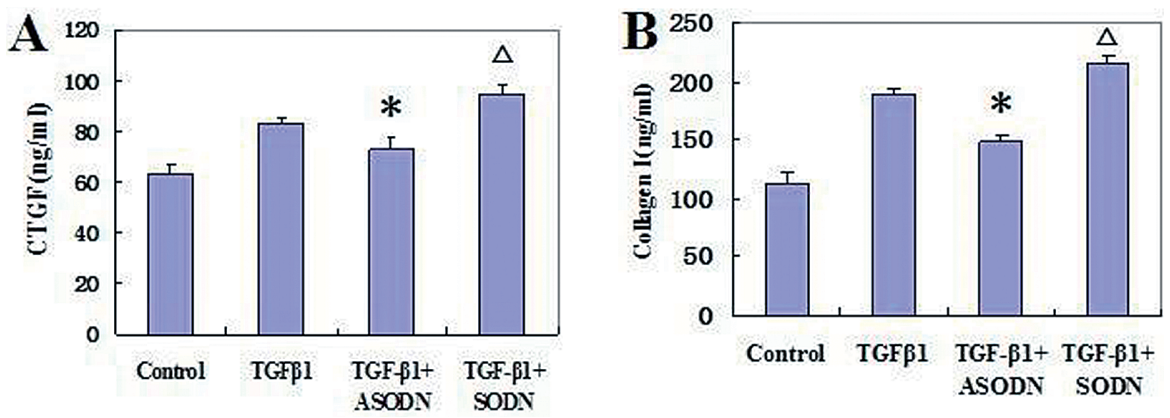

Fig. 5. Cell culture production of CTGF and Type I collagen. ELISA was used to determine the supernatant concentrations of (A) CTGF and (B) Type I collagen. Results were means \pm SEM $(n=3$ / group). ${ }_{p}<0.05$ (vs. control, TGF- $\beta 1$, TGF- $\beta 1+$ ASODN), ${ }^{*} p<0.05$ (vs. control, TGF- $\beta 1$, TGF$\beta 1+$ SODN). 

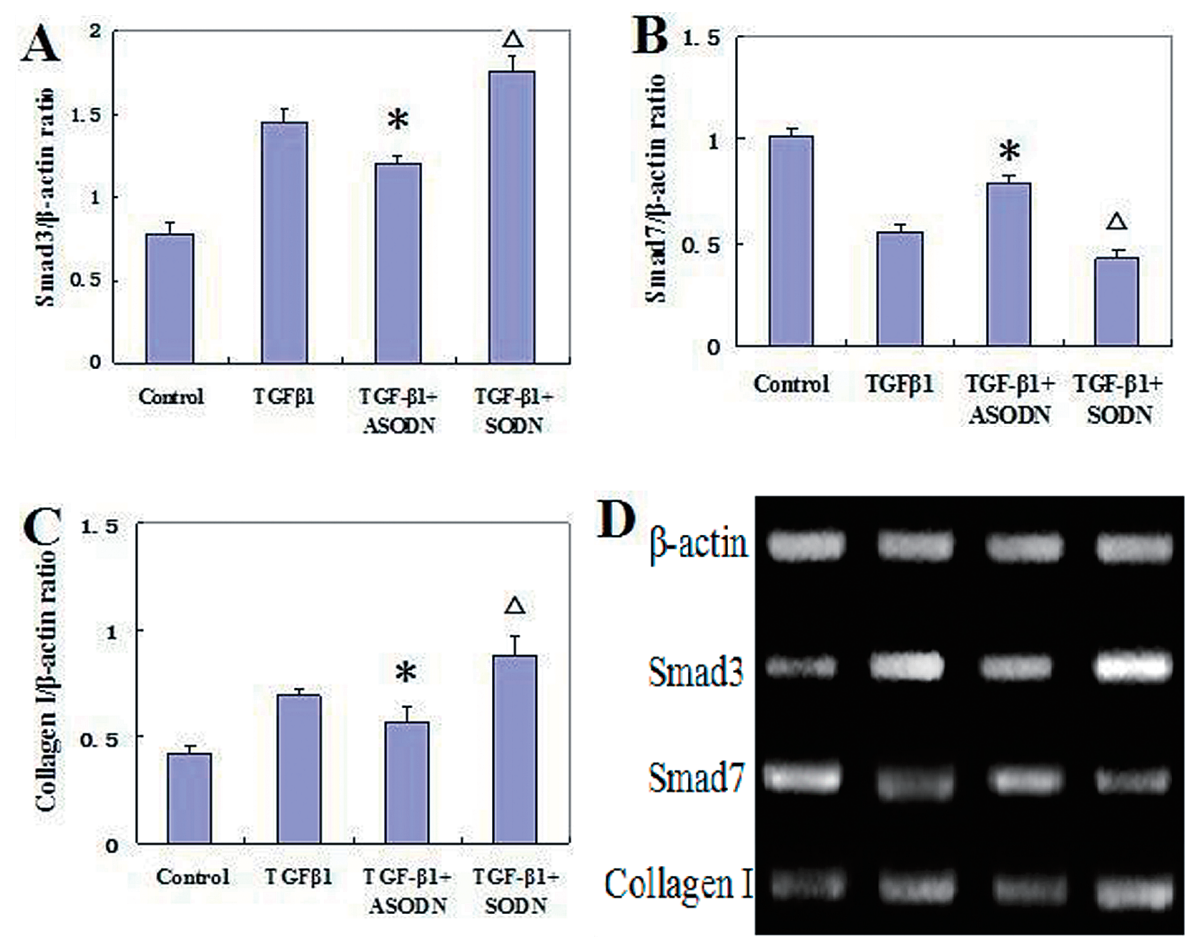

Fig. 6. The mRNA expression of Smad3, Smad7 and Type I collagen. RT-PCR was used to detect mRNA expression of (A) Smad3, (B) Smad7 and (C) Type I collagen. The ultraviolet absorbance at $260 \mathrm{~nm}$ was measured, and absorbance ratio of target gene to $\beta$-actin was taken as the relative value of target gene mRNA level. Results were means \pm SEM ( $n=3 /$ group). ${ }^{\triangle} p<0.05$ (vs. control, TGF- $\beta 1$, TGF- $\beta 1+$ ASODN), ${ }^{*} p<0.05$ (vs. control, TGF- $\beta 1$, TGF- $\beta 1+$ SODN).

significantly increased in the TGF- $\beta 1+$ SODN group than the TGF- $\beta 1$ and control groups $(p<0.05)$. However, the concentrations of them in the TGF- $\beta 1+$ ASODN group were higher than the control $(p<0.05)$ but lower than the TGF- $\beta 1$ group $(p<0.05)$. These results indicated that the secretion of CTGF and Type I collagen increased in the TGF- $\beta 1+$ SODN group and decreased in the TGF$\beta 1+$ ASODN group.

\section{The mRNA expression of Smad3, Smad7 and Type I collagen in pulmonary fibroblasts}

As shown in Fig. 6, the mRNA expressions of Smad3 (Fig. 6A) and Type I collagen (Fig. 6C) were significantly increased in the TGF- $\beta 1+$ SODN group than the TGF- $\beta 1$ and control groups $(p<0.05)$. However, the mRNA expressions of them in TGF- $\beta 1+$ ASODN group were higher than the control $(p<0.05)$ but lower than the TGF- $\beta 1$ group $(p<0.05)$. Meanwhile, the mRNA expression of Smad7 was just the opposite. These results indicated that SODN of bFGF increased the expression of Smad3 and decreased the expression of Smad7; however, ASODN of bFGF had the opposite effect. This effect was same for the expression of Type I collagen.

\section{Discussion}

Pulmonary fibrosis is a complex, chronic pathological change characterized by excessive fibroblast proliferation and aberrant deposition of extracellular matrix (ECM) proteins which result in irreversible distortion of the lung architecture and permanent loss of function (Noble et al. 2012). The activated lung fibroblasts and myofibroblasts which are the main components of fibroblast foci are recognized as key effector cells in producing ECM (Fernandez and Eickelberg 2012, 
Sivakumar et al. 2012, Lekkerkerker et al. 2012). The numbers of fibroblasts and myofibroblasts are correlated with worsening lung function, progression of disease, and poor prognosis (Flaherty et al. 2003). These suggest that the abnormal biological behavior of fibroblasts plays an important role in pulmonary fibrosis formation and development. Therefore, it can provide important information for treatment of pulmonary fibrosis to understand the pathogenetic mechanism of pulmonary fibroblast proliferation and differentiation.

Fibroblast growth factors (FGFs) are heparin-binding protein mitogens encoded by the FGF gene family which can stimulate the division of most cell types, such as endothelial cells, fibroblasts and keratinocyte. During embryonic development, FGFs play key roles in regulating cell proliferation, migration and differentiation. In adult tissues, FGFs are homeostatic factors and have important functions in mitogenesis, cellular migration, differentiation, angiogenesis, and wound healing (Yun et al. 2010, Moya et al. 2010, Shi et al. 2013). In the family of FGFs, basic fibroblast growth factor (bFGF) is the most studied factor. In lung disease, bFGF plays an extremely important role in lung cancer cells growth and tumor angiogenesis. Having the synergy with vascular endothelial growth factor (VEGF), bFGF promotes lung cancer cell proliferation, stimulates the formation of tumor blood vessels, and is associated with tumor metastasis (Grozio et al. 2007). Studies have shown that bFGF promotes the reconstruction of the vascular structure of COPD and reconstruction of asthma airway by stimulating the proliferation of fibroblasts and smooth muscle cells and being involved in angiogenesis and tissue regeneration process (Ward et al. 2004). In the research of pulmonary fibrosis, bFGF and TGF-beta have each been found to play a critical role in the different phases of bleomycin-induced pulmonary fibrosis by inducing fibroblast proliferation and transformation, respectively (Osaki et al. 2001). Excessive expression of VEGF-A, VEGF$\mathrm{C}, \mathrm{bFGF}$, and PDGF has been detected in cystic fibrosis airway epithelial cells (Verhaeghe et al. 2007). These evidences show that bFGF is involved in the process of pulmonary fibrosis.

Results from our research showed that bFGF which was increased by transfecting SODN of bFGF promoted the proliferation of pulmonary fibroblasts, while the proliferation of pulmonary fibroblasts was receded by ASODN of bFGF which could decrease the expression of bFGF. In addition, bFGF promoted the differentiation from fibroblast into myofibroblasts (increased $\alpha$-SMA expression) which was attenuated by inhibiting the secretion of bFGF. What's more, the synthesis of Type I collagen was markedly increased when the expression of bFGF was promoted by transfecting SODN of bFGF, however, ASODN of bFGF receded the synthesis of Type I collagen. Thus, our results suggest that bFGF facilitates pulmonary fibroblasts proliferation, differentiation and collagen synthesis which can be suppressed by inhibiting expression of bFGF.

Plenty of evidence has shown that fibroblast proliferation and phenotypic transformation is primarily related to excessive activation of TGF- $\beta$ signal pathway (Gharaee-Kermani et al. 2010, Yanagita 2012, Verrecchia and Mauviel 2007). TGF- $\beta$, which is produced predominantly by macrophages, plays a central role in the processes inducing EMT, driving differentiation of fibrocytes, and differentiation towards myofibroblasts (Verrecchia and Mauviel 2007, Lamouille et al. 2014, Harris et al. 2013). TGF- $\beta 1$ has been thought to be a critical molecule in pulmonary fibrosis, and play an important role in the process of pulmonary fibrosis. Increased expression of TGF- $\beta 1$ has been detected in lung tissues which are obtained from patients of idiopathic pulmonary fibrosis (Khalil et al. 1991). The fibrogenic role of TGF- $\beta 1$ is affirmed in animal models of pulmonary fibrosis, and the regulation of biological activities of TGF- $\beta 1$ has significantly decreased the degree of fibrosis in these models (Das et al. 2014, Song et al. 2013).

Following extracellular activation of TGF- $\beta$, smads protein mediates intracellular signal transmission (Mehra and Wrana 2002). Smads are a kind of highly conserved protein family with a molecular weight of $42-60 \mathrm{kDa}$ (Matsuzaki 2013). They can be divided into three categories based on structural and functional characteristics: receptor regulated smads (it was smad $2 / 3$ that was related to TGF- $\beta 1$ signal transduction), common mediator (primarily smad4), and inhibitory 
smads (consisting of smad6 and smad7) (Leask and Abraham 2004, Verrecchia and Mauviel 2002). Smad3 can promote fibroblast proliferation and phenotypic transformation as well as synthesis and secretion of extracellular matrix, playing a key role in the TGF- $\beta 1$ signal transduction (Isono et al. 2002). Smad7 is the main inhibitory regulatory protein of TGF- $\beta$ signal pathway, which can competitively bind the TGF- $\beta 1$ receptor (Saika et al. 2007).

In our research, rat pulmonary fibroblast was stimulated by TGF- $\beta 1$. Results showed that the mRNA expression of Smad3 was significantly increased and the mRNA expression of Smad7 was markedly decreased when the synthesis of bFGF was increased by transfecting SODN of bFGF. However, inhibiting the synthesis of bFGF by transfecting ASODN of bFGF could reduce TGF$\beta 1$-induced Smad 3 mRNA expression and promote TGF- $\beta 1$-induced Smad7 mRNA expression. In addition, our research found that connective tissue growth factor (CTGF) was high expressed in the condition of transfecting SODN of bFGF, while the expression CTGF was decreased following the synthesis of bFGF suppressed by transfecting ASODN of bFGF. CTGF, which is stimulated by TGF- $\beta 1$, is an important cell factor in pulmonary fibrosis (Fu et al. 2011, Lai et al. 2009). These indicate that bFGF can up-regulate the expression of Smad3 and down-regulate the expression of Smad7 in TGF- $\beta 1$ stimulated lung fibroblasts, and this effect can be inhibited by ASODN of bFGF. Moreover, bFGF can promote the expression of CTGF and the ASODN of bFGF inhibits TGF- $\beta 1$ induced synthesis of CTGF.

In conclusion, this study demonstrates that the increased expression of bFGF promotes TGF$\beta 1$-induced pulmonary fibroblast proliferation, differentiation and collagen synthesis, and the possible mechanism is associated with the regulation of TGF- $\beta 1$-Smad signaling pathway. The ASODN of bFGF can inhibit this effect by down-regulating the expression of CTGF and Smad3 and up-regulating the expression of Smad7. Our research provides a new perspective about the treatment of pulmonary fibrosis.

\section{References}

American Thoratic Society and European Respiratory Society European Respiratory Society 2002. American thoracic society/european respiratory society international multidisciplinary consensus classification of the idiopathic interstitial pneumonias. Am. J. Respir. Crit. Care Med. 165: 277-304.

Berndt, A., Kosmehl, H., Mandel, U., Gabler, U., Luo, X., Celeda, D., Zardi, L. and Katenkamp, D. 1995. TGF beta and bFGF synthesis and localization in Dupuytren's disease (nodular palmar fibromatosis) relative to cellular activity, myofibroblast phenotype and oncofetal variants of fibronectin. Histochem. J. 27: 1014-1020.

Cheng, Z., Yang, J. and Ye, Y. 2012. Mast cells induce rat pulmonary fibroblast proliferation and differentiation via direct cell-cell contact. Cytologia 77: 1-9.

Das, S., Kumar, M., Negi, V., Pattnaik, B., Prakash, Y. S., Agrawal, A. and Ghosh, B. 2014. MicroRNA-326 regulates pro-fibrotic functions of transforming growth factor- $\beta$ in pulmonary fibrosis. Am. J. Respir. Cell Mol. Biol. 50: $882-892$.

Davis, M. G., Zhou, M., Ali, S., Coffin, J. D., Doetschman, T. and Dorn, G. W. II 1997. Intracrine and autocrine effects of basic fibroblast growth factor in vascular smooth muscle cells. J. Mol. Cell. Cardiol. 29: 1061-1072.

Fernandez, I. E. and Eickelberg, O. 2012. New cellular and molecular mechanisms of lung injury and fibrosis in idiopathic pulmonary fibrosis. Lancet 380: 680-688.

Flaherty, K. R., Colby, T. V., Travis, W. D., Toews, G. B., Mumford, J., Murray, S., Thannickal, V. J., Kazerooni, E. A., Gross, B. H., Lynch, J. P. 3rd and Martinez, F. J. 2003. Fibroblastic foci in usual interstitial pneumonia: Idiopathic versus collagen vascular disease. Am. J. Respir. Crit. Care Med. 167: 1410-1415.

Fu, J. H., Yang, H. P., Pan, L., Xue, X. D. and Gao, H. 2011. Effects of TGF- $\beta 1$ on gene expression of connective tissue growth factor in lung fibroblasts. Zhongguo Dang Dai Er Ke Za Zhi 13: 36-39.

Gharaee-Kermani, M., Hu, B., Phan, S. H. and Gyetko, M. R. 2010. Recent advances in molecular targets and treatment of idiopathic pulmonary fibrosis: Focus on TGFbeta signaling and the myofibroblast. Curr. Med. Chem. 16: 1400-1417.

Grozio, A., Catassi, A., Cavalieri, Z., Paleari, L., Cesario, A. and Russo, P. 2007. Nicotine, lung and cancer. Anticancer. Agents Med. Chem. 4: 461-466.

Harris, W. T., Kelly, D. R., Zhou, Y., Wang, D., Macewen, M., Hagood, J. S., Clancy, J. P., Ambalavanan, N. and Sorscher, 
E. J. 2013. Myofibroblast differentiation and enhanced TGF-B signaling in cystic fibrosis lung disease. PLoS ONE 8: e70196.

Henke, C., Fiegel, V., Peterson, M., Wick, M., Knighton, D., McCarthy, J. and Bitterman, P. 1991. Identification and partial characterization of angiogenesis bioactivity in the lower respiratory tract after acute lung injury. J. Clin. Invest. 88: 1386-1395.

Inoue, Y., King, T. E. Jr., Tinkle, S. S., Dockstader, K. and Newman, L. S. 1996. Human mast cell basic fibroblast growth factor in pulmonary fibrotic disorders. Am. J. Pathol. 149: 2037-2054.

Isono, M., Chen, S., Hong, S. W., Iglesias-de la Cruz, M. C. and Ziyadeh, F. N. 2002. Smad pathway is activated in the diabetic mouse kidney and Smad3 mediates TGF-beta-induced fibronectin in mesangial cells. Biochem. Biophys. Res. Commun. 296: 1356-1365.

Khalil, N., O'Connor, R. N., Unruh, H. W., Warren, P. W., Flanders, K. C., Kemp, A., Bereznay, O. H. and Greenberg, A. H. 1991. Increased production and immunohistochemical localisation of transforming growth factor-beta in idiopathic pulmonary fibrosis. Am. J. Respir. Cell Mol. Biol. 5: 155-162.

Lai, T. C., Pociask, D. A., Ferris, M., Nguyen, H. T., Miller, C. A. 3rd, Brody, A. and Sullivan, D. 2009. Small interfering RNAs (siRNAs) targeting TGF-betal mRNA suppress asbestos-induced expression of TGF-betal and CTGF in fibroblasts. J. Environ. Pathol. Toxicol. Oncol. 28: 109-119.

Lamouille, S., Xu, J. and Derynck, R. 2014. Molecular mechanisms of epithelial-mesenchymal transition. Nat. Rev. Mol. Cell Biol. 15: 178-196.

Leask, A. and Abraham, D. J. 2004. TGF-beta signaling and the fibrotic response. FASEB J. 18: 816-827.

Lee, C. M., Park, J. W., Cho, W. K., Zhou, Y., Han, B., Yoon, P. O., Chae, J., Elias, J. A. and Lee, C. G. 2014. Modifiers of TGF-beta 1 effector function as novel therapeutic targets of pulmonary fibrosis. Korean J. Intern. Med. 29: 281-290.

Lekkerkerker, A. N., Aarbiou, J., van Es, T. and Janssen, R. A. 2012. Cellular players in lung fibrosis. Curr. Pharm. Des. 18: 4093-4102.

Matsuzaki, K. 2013. Smad phospho-isoforms direct context-dependent TGF-beta signaling. Cytokine Growth Factor Rev. 24: 385-399.

Mehra, A. and Wrana, J. L. 2002. TGF-beta and the Smad signal transduction pathway. Biochem. Cell Biol. 80: 605-622.

Moya, M. L., Cheng, M. H., Huang, J. J., Francis-Sedlak, M. E., Kao, S. W., Opara, E. C. and Brey, E. M. 2010. The effect of FGF-1 loaded alginate microbeads on neovascularization and adipogenesis in a vascular pedicle model of adipose tissue engineering. Biomaterials 31: 2816-2826.

Noble, P. W., Barkauskas, C. E. and Jiang, D. 2012. Pulmonary fibrosis: Patterns and perpetrators. J. Clin. Invest. 122: 2756-2762.

Osaki, T., Yoneda, K., Tatemoto, Y., Yamamoto, T., Yokoyama, T. and Enzan, H. 2001. Peplomycin, a bleomycin derivative, induces myofibroblasts in pulmonary fibrosis. Int. J. Exp. Pathol. 82: 231-241.

Qu, Z., Liebler, J. M., Powers, M. R., Galey, T., Ahmadi, P., Huang, X. N., Ansel, J. C., Butterfield, J. H., Planck, S. R. and Rosenbaum, J. T. 1995. Mast cells are a major source of basic fibroblast growth factor in chronic inflammation and cutaneous hemangioma. Am. J. Pathol. 147: 564-573.

Reed, J. A., Albino, A. P. and McNutt, N. S. 1995. Human cutaneous mast cells express basic fibroblast growth factor. Lab. Invest. 72: 215-222.

Saika, S., Yamanaka, O., Nishikawa-Ishida, I., Kitano, A., Flanders, K. C., Okada, Y., Ohnishi, Y., Nakajima, Y. and Ikeda, K. 2007. Effect of Smad7 gene overexpression on transforming growth factor beta-induced retinal pigment fibrosis in a proliferative vitreoretinopathy mouse model. Arch. Ophthalmol. 125: 647-654.

Shi, H. X., Lin, C., Lin, B. B., Wang, Z. G., Zhang, H. Y., Wu, F. Z., Cheng, Y., Xiang, L. J., Guo, D. J., Luo, X., Zhang, G. Y., Fu, X. B., Bellusci, S., Li, X. K. and Xiao, J. 2013. The anti-scar effects of basic fibroblast growth factor on the wound repair in vitro and in vivo. PLoS ONE 8: e59966.

Sivakumar, P., Ntolios, P., Jenkins, G. and Laurent, G. 2012. Into the matrix: Targeting fibroblasts in pulmonary fibrosis. Curr. Opin. Pulm. Med. 18: 462-469.

Song, X., Liu, W., Xie, S., Wang, M., Cao, G., Mao, C. and Lv, C. 2013. All-transretinoic acid ameliorates bleomycininduced lung fibrosis by downregulating the TGF- $\beta 1 / \mathrm{Smad} 3$ signaling pathway in rats. Lab. Invest. 93: 12191231.

Verhaeghe, C., Tabruyn, S. P., Oury, C., Bours, V. and Griffioen, A. W. 2007. Intrinsic pro-angiogenic status of cystic fibrosis airway epithelial cells. Biochem. Biophys. Res. Commun. 356: 745-749.

Verrecchia, F. and Mauviel, A. 2002. Transforming growth factor-beta signaling through the Smad pathway: Role in extracellular matrix gene expression and regulation. J. Invest. Dermatol. 118: 211-215.

Verrecchia, F. and Mauviel, A. 2007. Transforming growth factor-beta and fibrosis. World J. Gastroenterol. 13: 30563062 .

Ward, J. E., Gould, H., Harris, T., Bonacci, J. V. and Stewart, A. G. 2004. PPAR gamma ligands, 15-deoxy-delta12, 14-prostaglandin $\mathrm{J} 2$ and rosiglitazone regulate human cultured airway smooth muscle proliferation through dif- 
ferent mechanisms. Br. J. Pharmacol. 141: 517-525.

Wolters, P. J., Collard, H. R. and Jones, K. D. 2014. Pathogenesis of idiopathic pulmonary fibrosis. Annu. Rev. Pathol.: Mech. Dis 9: 157-179.

Yanagita, M. 2012. Inhibitors/antagonists of TGF-beta system in kidney fibrosis. Nephrol. Dial. Transplant. 27: 36863691.

Yun, Y. R., Won, J. E., Jeon, E., Lee, S., Kang, W., Jo, H., Jang, J. H., Shin, U. S. and Kim, H. W. 2010. Fibroblast growth factors: Biology, function, and application for tissue regeneration. J. Tissue Eng. 2010: 218142. 